\title{
Supramolecular alloys from fluorinated hybrid [4+6] imine
}

\section{cages}

\author{
Tom Kunde, ${ }^{\ddagger}$ Tobias Pausch ${ }^{\ddagger}$ and Bernd M. Schmidt ${ }^{\star}$ \\ Tom Kunde, Tobias Pausch and Bernd M. Schmidt \\ Institut für Organische Chemie und Makromolekulare Chemie \\ Heinrich-Heine-Universität Düsseldorf \\ Universitätsstraße 1, D-40225 Düsseldorf, Germany \\ E-mail: Bernd.Schmidt@hhu.de \\ Homepage: http://www.bmschmidtlab.de
}

\begin{abstract}
To create innovative materials, efficient control and engineering of pore sizes and their characteristics, crystallinity and stability is required. Eight hybrid [4+6] imine cages with a tuneable degree of fluorination and one fully fluorinated [4+6] imine cage are investigated. Although the fluorinated and the non-fluorinated building blocks used herein differ vastly in reactivity, we are able to gain control over the outcome of the self-assembly process, by carefully controlling the feed ratio. This represents the first hybrid material based on fluorinated/hydrogenated porous organic cages (POCs). These alloys with unlimited miscibility in the solid state were obtained as highly crystalline samples after recrystallization and even showed retention of the crystal lattice. All alloys and the fully fluorinated [4+6] imine cage were analysed by MALDI-MS, SCXRD, PXRD and in regards to thermal stability (TGA).
\end{abstract}

Nature efficiently uses the principles of non-covalent self-assembly together with self-sorting phenomena to generate complex, functional architectures from several different and often complex building blocks bearing function. In an abiological context, the design of porous materials, suitable for gas adsorption applications, requires precise control over the interior and exterior pore size, accessibility and the stability of the material itself. ${ }^{[1]}$ A large range of materials, containing a high amount of fluorine atoms, have in the past been attributed with increased thermal stability, higher crystallinity and higher gas uptake compared to their nonfluorinated counterparts. ${ }^{[2-5]}$ The group of Miljanić was able to capture fluorinated anaesthetics inside a porous crystal, consisting of extensively fluorinated aromatic molecules. ${ }^{[6 a, b]}$ The beneficial effect of fluorine substitution does even further extend to increased crystallinity, not only in the crystal lattice of small molecules, but also in COFs. ${ }^{[5,7]}$ Dynamic covalent bond formation, often employing amine and aldehyde building blocks for self-correcting imine formation, generates dynamic cage-type compounds with various properties up to complex multicomponent libraries. ${ }^{[8]}$ Porous organic cages (POCs), as an emerging class of porous materials, have been extensively studied throughout the last decade. ${ }^{[9 a, c, 10 e-g]}$ Significant contributions include control of pore size ${ }^{[9 \mathrm{gb}, \mathrm{e}, 10 \mathrm{~b}]}$ cage and pore geometry, ${ }^{\left[{ }^{9 f]}\right.}$ guest binding behaviour ${ }^{[10 \mathrm{~g}]}$ and engineering of the overall crystal packing, ${ }^{[9 \mathrm{f}, 10 \mathrm{ff}]}$ demonstrating a great degree of control over the material properties. ${ }^{[9,10]}$ Only few articles focus on the role of fluorine in dynamic imine chemistry and as the possibility to influence porosity and guest-binding behaviour of POCs. ${ }^{[10 b, 11]}$ Recently, we were able to demonstrate the beneficial effect of fluorine substitution towards gas adsorption of POCs. ${ }^{[13]}$ We investigate the synthesis of hybridPOCs containing non-fluorinated and fluorinated building blocks, resulting in a complex dynamic material library. We examine the different reactivities of the two isostructural aldehydes and their influence on the outcome of dynamic [4+6] imine condensations. The effect of fluorine substitution on the thermal stability and crystallinity of these novel hybrid materials is analysed to evaluate the result of our library approach. In the high-throughput study of Cooper and co-workers, the formation of a [4+6] imine cage by reaction of four 1,3,5tris(2-aminomethyl)-2,4,6-triethyl-benzene (A) units with six terephthalaldehyde molecules (TA) was reported. ${ }^{\left[{ }^{[d]}\right]}$ We chose this motif to subsequently exchange the six non-fluorinated 
TA building blocks for tetrafluoroterephthalaldehyde (TFTA), allowing us to precisely monitor the influence of fluorinated subunits in relation to cage properties (solid state self-assembly and thermal stability). The large difference in electron density and overall quadrupolar moment is envisioned to have a significant effect on the cavity of the resulting imine cages. We present a series of eight partially fluorinated imine cages, as well as a fully fluorinated $[4+6]$ imine cage using building blocks with a large difference in reactivity for the first time.

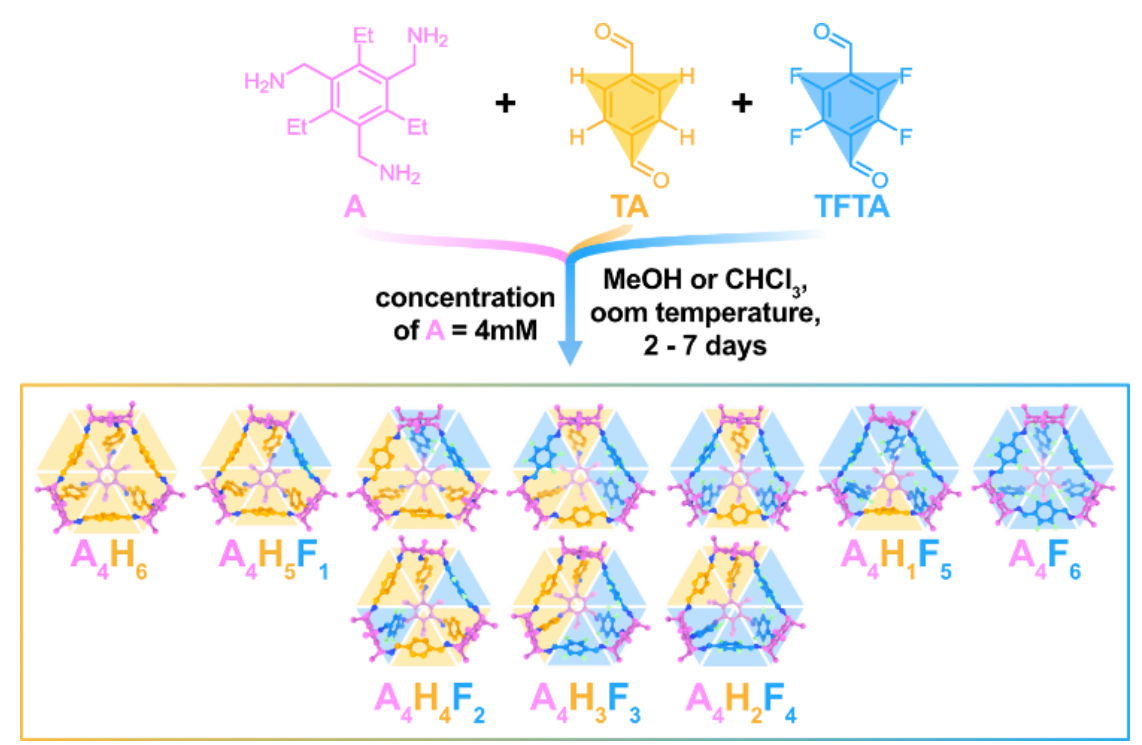

Figure 1. Synthetic scheme of the reaction of amine A with TA and fluorinated TFTA, in different feed ratios, targeting the hybrid cages $\mathbf{A}_{4} \mathbf{H}_{\mathbf{x}} \mathbf{F}_{(6-\mathrm{x})}$; the hexagons indicate the corresponding compositions of the hybrid cages throughout the manuscript.

Previous studies utilized chiral self-sorting ${ }^{[10 c]}$ or structurally different building blocks to desymmetrize POCs by imine condensation to create amorphous materials. ${ }^{[14]}$ Along with increasing disorder within the material, this approach allows us to generate a crystalline supramolecular alloy, freely composed of highly fluorinated and non-fluorinated POCs. ${ }^{[15]}$

Five equivalents of amine A (slight excess) were reacted with varying ratios of TA and TFTA at room temperature in either methanol or chloroform with an amine concentration of $4 \mathrm{mmol} / \mathrm{L}$. As a systematic nomenclature for these mixed cages we use $A_{4} H_{x} F_{(6-x)}$ herein, where $X$ is the number of incorporated TA molecules and the number following the letter $\mathbf{F}$ represents the number of TFTA moieties per cage molecule (Figure 1). After a period of 2 days, we could isolate a colourless solid directly from the reaction mixture by filtration. Analysis by ${ }^{1} \mathrm{H},{ }^{19} \mathrm{~F}$ NMR and DOSY experiments after redissolving the solids revealed the successful synthesis of a narrow distribution of hybrid cage species around the targeted composition (Figure 2). All alloys following the composition $\mathbf{A}_{4} \mathbf{H}_{\mathrm{x}} \mathbf{F}_{(6-\mathrm{x})}$, are expected to be of similar size and indeed show comparable diffusion coefficients around $D=4.5^{\star} 10^{-10} \mathrm{~m}^{2} \mathrm{~s}^{-1}$ corresponding to a solvodynamic radius of $0.90 \mathrm{~nm}$ in solution (Table $\mathrm{S} 1$ ). A statistical distribution of the mixed cages $\mathbf{A}_{4} \mathbf{H}_{5} \mathbf{F}_{1}$, $\mathrm{A}_{4} \mathrm{H}_{4} \mathrm{~F}_{2}$ and $\mathrm{A}_{4} \mathrm{H}_{3} \mathrm{~F}_{3}$ alongside $\mathrm{A}_{4} \mathrm{H}_{6}$ is also confirmed by MALDI-MS analysis of the precipitate. According to the general procedure, to our delight, all anticipated hybrid cage mixtures with varying fluorine content can be accessed and were characterized as obtained from the reaction mixture comprehensively by using MALDI-MS, NMR and powder XRD (Figure S39 and S46S68). Directly corresponding to the feed ratio of TA and TFTA, a narrow gaussian-like distribution around the targeted composition demonstrates very good control over the outcome of the cage formation (Figure 2). 

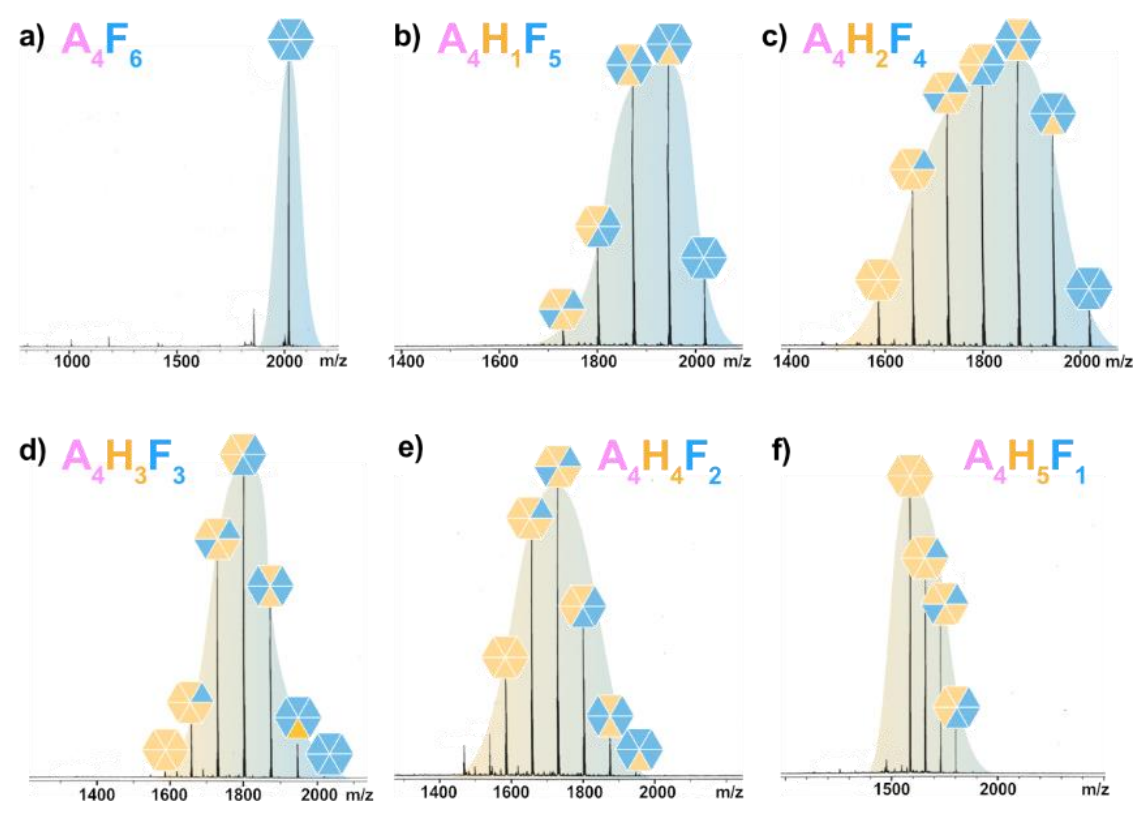

Figure 2. MALDI-MS spectra of the isolated cage alloys a) $\mathbf{A}_{4} \mathbf{F}_{6}$, b) $\mathbf{A}_{4} \mathbf{H}_{1} \mathbf{F}_{5}$, c) $\mathbf{A}_{4} \mathbf{H}_{2} \mathbf{F}_{4}$, d) $\mathbf{A}_{4} \mathbf{H}_{3} \mathbf{F}_{3}$, e) $\mathbf{A}_{4} \mathbf{H}_{4} \mathbf{F}_{2}$, f) $\mathbf{A}_{4} \mathrm{H}_{5} \mathrm{~F}_{1}$ obtained using different feed ratios of TA and TFTA with 5 equivalents of amine $\mathbf{A}$, inlays each indicate the targeted composition. Using a slight excess of amine A, yields are significantly improved. ${ }^{[9 d]}$ The compounds were isolated directly from the reaction mixture by either filtration or evaporation of the solvent at ambient temperatures.

Considering TFTA bears four highly electronegative substituents, we were intrigued to examine the differences in reactivity compared to TA, since the synthesis of imine cages is often accompanied by precipitation of the product from the reaction solvent. In those cases, the time until precipitation occurs, can serve as an indicator for reactivity. To study these differences, chloroform was chosen as solvent. In our experience, possible oligomeric side products are solubilized efficiently in chloroform, facilitating error correction of dynamic imine condensation reactions. Under these given conditions, pure $A_{4} \mathrm{H}_{6}$ and $\mathrm{A}_{4} \mathrm{H}_{5} \mathrm{~F}_{1}$ mixtures start to precipitate after $24 \mathrm{~h}$, whereas all cage alloys with a TFTA count $>1$ start precipitating almost immediately (as indicated by NMR experiments, Figure S1-S2). This underlines the anticipated high reactivity of the TFTA molecules and hence, shorter reaction times. To further investigate the different reactivities, we conducted kinetic NMR experiments and DFT calculations (Figure S1-S4 and S17). The two approaches to generate essentially all $\mathrm{A}_{4} \mathrm{H}_{\mathrm{x}} \mathrm{F}_{(6-\mathrm{X})}$ species are: a) by mixing the pure $A_{4} F_{6}$ and $A_{4} H_{6}$ cages in the corresponding ratios to generate a distribution of mixed cage compounds in hot chloroform over prolonged time (Figure S6-S7) or b), by mixing TFTA and TA with the amine $A$ in ratios corresponding to the targeted $\mathrm{A}_{4} \mathrm{H}_{\mathrm{X}} \mathrm{F}_{(6-\mathrm{x})}$ composition. The latter approach is clearly faster since the reaction times are only 2-3 days instead of several weeks needed for the former system to reach its equilibrium state.

Immediately after mixing, the consumption of TFTA can be observed. Fast formation of precipitate (potentially oligomeric species with high fluorine content) can be noted, without new imine signals in ${ }^{1} \mathrm{H}$ NMR being observed. TFTA is consumed completely, before the majority of TA reacted. The oligomeric species containing TFTA appear to act as a reservoir and are not removed from the system completely (Figure S1-S2). Redissolved fragments react then with the less reactive TA building blocks in a dynamic equilibrium, resulting in the observed mixtures, an important addition to the recent investigation on hydrogenated and deuterated POCs. ${ }^{[16]}$

As anticipated, the decomposition temperatures are increasing with higher fluorine content. The onset temperature of $\mathbf{A}_{4} \mathbf{H}_{6}, 266{ }^{\circ} \mathrm{C}$ could be increased to $313{ }^{\circ} \mathrm{C}$ for $\mathbf{A}_{4} \mathbf{F}_{6}$. Each subsequent substitution of TA versus TFTA increases the decomposition onset by roughly 5 
${ }^{\circ} \mathrm{C}$ (Figure 3e). This is in perfect agreement with the influence of fluorine substitution on porous organic materials. ${ }^{[2 \mathrm{~d}]}$ We were able to obtain single-crystals (Figure $3 \mathrm{a}$ ) of all targeted imine cage compounds and obtained structural data for pure $\mathbf{A}_{4} \mathbf{F}_{6}$ and $\mathbf{A}_{4} \mathbf{H}_{1} \mathbf{F}_{5}, \mathbf{A}_{4} \mathbf{H}_{2} \mathbf{F}_{\mathbf{4}}, \mathbf{A}_{\mathbf{4}} \mathbf{H}_{4} \mathbf{F}_{\mathbf{2}}$ alloys. The hybrid cages crystallize in regular rhombohedral shapes (Figure $3 \mathrm{c}$ ). To our surprise, the single-crystals also did not consist of one cage isomer but exhibited the same gaussian distribution of hybrid cages, within the crystal lattice (Figure S61-S67). All hybrid cage alloys crystallize in the highly symmetric rhombohedral space group $R-3$, with one whole and a third molecule $\mathbf{A}$ and two para-substituted building blocks in the asymmetric unit. Due to their large size and voids containing ordered and disordered solvent molecules within the lattice, refinement was carried out as described for each crystal (Page S29 ff.). The TFTA and TA motifs can be exchanged freely in the crystal lattice at the two available, crystallographically independent positions and are furthermore moved by the representative symmetry operations. The average fluorine content was estimated from the diffraction data and compared to MALDIMS data of the single-crystals, showing excellent agreement. In the solid state, two adjacent cages pack window-to window generating a pore of roughly $18 \AA$ length, as depicted (Figure $3 d$ ). Close $\pi$ - $\pi$-stacking in a distance of about $3.5 \AA$ connects neighbouring cages, whereas stacking with former amine building block $\mathbf{A}$ is hampered by the bulky ethyl groups, leading to centroid-to-centroid distances of around $4.5 \AA$. These results suggest a) the influence of fluorinated building blocks on the crystallinity, as only the non-fluorinated imine cage could not be crystallized and b) an interchangeability of TFTA and TA both in the parent cage and in the crystal lattice of these [4+6] imine cages (Figure 3b), making them indeed tuneable supramolecular alloy materials in the solid state.

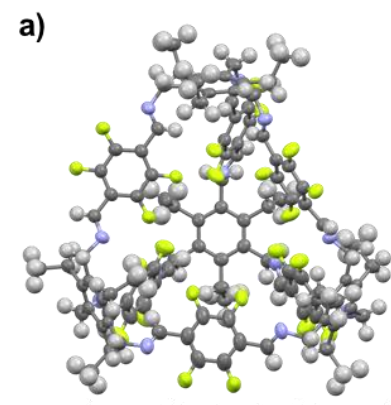

d)
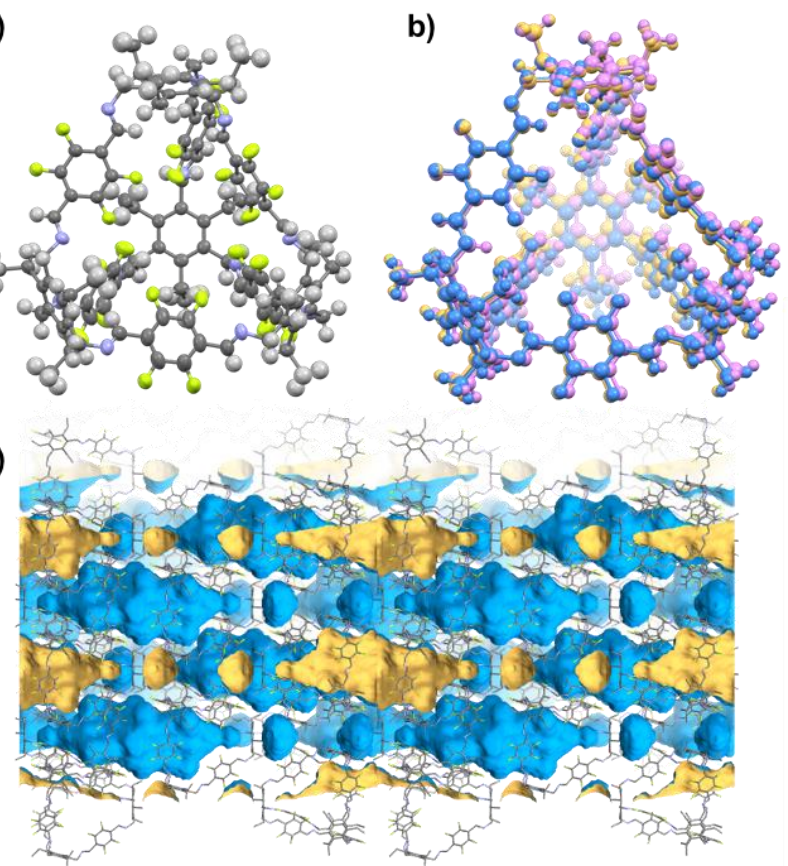

c)
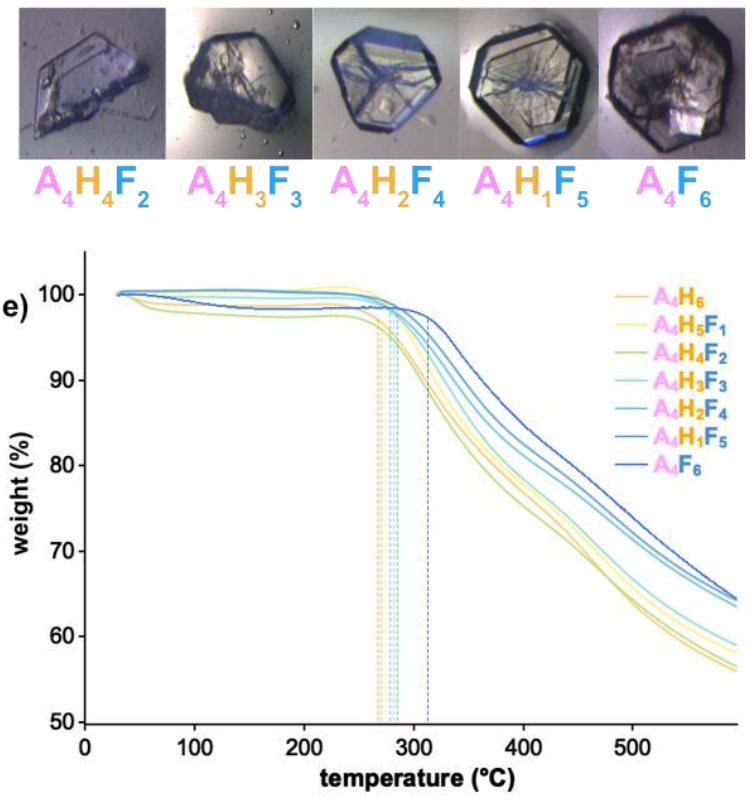

Figure 3. a) Structure of $\mathrm{A}_{4} \mathrm{H}_{2} \mathrm{~F}_{4}$ obtained from SXRD data; the structure was measured at $100 \mathrm{~K}$ and solved in the rhombohedral $R-3$ with $R_{\operatorname{lnt}}=0.1182, R_{1}=0.0931$ and $w R_{2}=0.3157$, the fluorine content is estimated to be 48 percent for both crystallographically unequal fluorobenzenes within the structure (the variance is the highest for $\mathrm{A}_{4} \mathrm{H}_{2} \mathrm{~F}_{4}$ because of a low resolution and framework disorder, see the SI); solvents are omitted for clarity; b) overlay of the crystal structures for $\mathbf{A}_{4} \mathbf{F}_{6}$ (blue), $\mathbf{A}_{4} \mathbf{H}_{1} \mathbf{F}_{5}$ (pink) and $\mathbf{A}_{4} \mathbf{H}_{2} \mathbf{F}_{4}$ (orange); c) microscopic photographs taken of single-crystals before XRD measurements; d) solvent accessible surface area without solvents for a molecular probe with $1.2 \AA$ radius (outer surface area = blue, inner surface = orange) within the crystal lattice; e) thermogravimetric analyses of all hybrid cage alloys; the dotted lines indicate the onset temperature of decomposition (Table S2).

We successfully synthesized and characterized a family of dynamic [4+6] imine cages, $\mathrm{A}_{4} \mathrm{H}_{\mathrm{x}} \mathrm{F}_{(6-\mathrm{x})}$, containing highly fluorinated building blocks. To the best of our knowledge, this is 
the first report of a crystalline supramolecular alloy based on POCs. The introduction of electron-deficient and therefore highly reactive aldehydes in any given ratio increases the stability and crystallinity of the obtained material in a step-wise fashion, without influencing the overall crystal packing. A formation study using different feed ratios suggests a faster reaction of fluorinated aldehydes in comparison to the non-fluorinated counterparts, where imine cage $\mathbf{A}_{4} \mathrm{H}_{6}$ is formed slower. The fine tuning of the cavity of an organic cage will enable precise control over the selectivity of the resulting solid state materials in the future and marks an entry point for fluorinated organic cages into the field of supramolecular materials chemistry. Our study is an important addition to the dynamic covalent chemistry of complex POCs, employing three or more building blocks and lays the foundation for further research regarding exciting properties of this new class of organic cages.

\section{Acknowledgements}

We thank Dr. Markus Leutzsch of the MPI for Coal Research for help with the NMR measurements and Dr. Raphael Wiedey and Prof. Dr. Peter Kleinebudde for access to a powder X-ray diffractometer. This work was supported by the Fonds der Chemischen Industrie by a Kekulé Fellowship (T.K.) by the North Rhine-Westphalian Academy of Sciences, Humanities and the Arts (B.M.S.) and funded by the Deutsche Forschungs-gemeinschaft (DFG, German Research Foundation) - SCHM 3101/5-1.

\section{References}

[1] a) A. G. Slater, A. I. Cooper, Science 2015, 348, aaa8075; b) T. Hasell, A. I. Cooper, Nat. Rev. Mat. 2016, 1, 16053.

[2] a) A. Cadiau, Y. Belmabkhout, K. Adil, P. M. Bhatt, R. S. Pillai, A. Shkurenko, C. MartineauCorcos, G. Maurin, M. Eddaoudi, Science 2017, 356, 731-735; b) T.-H. Chen, I. Popov, O. Zenasni, O. Daugulis, O. Š. Miljanić, Chem. Commun. 2013, 49, 6846-6848; c) P. Pachfule, Y. Chen, J. Jiang, R. Banerjee, Chem. Eur. J. 2012, 18, 688-694; a recent review: d) Z. Zhang, O. Š. Miljanić, Org. Mat. 2019, 1, 19-29.

[3] a) C. Yang, X. Wang, M. A. Omary, J. Am. Chem. Soc. 2007, 129, 15454-15455; b) C. Yang, U. Kaipa, Q. Z. Mather, X. Wang, V. Nesterov, A. F. Venero, M. A. Omary, J. Am. Chem. Soc. 2011, 133, 18094-18097; for recent reviews on fluorinated MOFs, see: c) K. Jayaramulu, F. Geyer, A. Schneemann, Š. Kment, M. Otyepka, R. Zboril, D. Vollmer, R. A. Fischer, Adv. Mater. 2019, 31, 1900820; d) S.-I. Noro, T. Nakamura, NPG Asia Materials, 2017, 9, e433.

[4] a) P. M. Bhatt, Y. Belmabkhout, A. Cadiau, K. Adil, O. Shekhah, A. Shkurenko, L. J. Barbour, M. Eddaoudi, J. Am. Chem. Soc. 2016, 138, 9301-9307; b) T.-H. Chen, I. Popov, W. Kaveevivitchai, Y.-C. Chuang, Y.-S. Chen, A. J. Jacobson, O. Š. Miljanić, Angew. Chem. Int. Ed. 2015, 54, 13902-13906.

[5] a) A. Comotti, F. Castiglioni, S. Bracco, J. Perego, A. Pedrini, M. Negroni, P. Sozzani, Chem. Commun. 2019, 55, 8999-9002; b) G. Wang, K. Leus, H. S. Jena, C. Krishnaraj, S. Zhao, H. Depauw, N. Tahir, Y.-Y. Liu, P. Van Der Voort, J. Mat. Chem. A, 2018, 6, 6370-6375; c) S. B. Alahakoon, G. T. McCandless, A. A. K. Karunathilake, C. M. Thompson, R. A. Smaldone, Chem. Eur. J. 2017, 23, 4255-4259.

[6] a) T.-H. Chen, I. Popov, W. Kaveevivitchai, Y.-C. Chuang, Y.-S. Chen, O. Daugulis, A. J. Jacobson, O. Š. Miljanić, Nat. Commun. 2014, 5, 5131; b) Z. Yang, S. Wang, Z. Zhang, W. Guo, K. Jie, M. I. Hashim, O. Š. Miljanić, D.-E. Jiang, I. Popovs, S. Dai, J. Mat. Chem. A, 2019, 7, 17277-17282. c) T.-H. Chen, W. Kaveevivitchai, A. J. Jacobson, O. Š. Miljanić, Chem. Commun. 2015, 51, 14096-14098. 
[7] a) M. I. Hashim, H. T. M. Le, T.-H. Chen, Y.-S. Chen, O. Daugulis, C.-W. Hsu, A. J. Jacobson, W. Kaveevivitchai, X. Liang, T. Makarenko, O. Š. Miljanić, I. Popovs, H. V. Tran, X. Wang, C.-H. Wu, J. I. Wu, J. Am. Chem. Soc. 2018, 140, 6014-6026; b) J.-H. Dou, Y.-Q. Zheng, Z.-F. Yao, Z.-A. Yu, T. Lei, X. Shen, X.-Y. Luo, J. Sun, S.-D. Zhang, Y.-F. Ding, G. Han, Y. Yi, J.-Y. Wang, J. Pei, J. Am. Chem. Soc. 2015, 137, 15947-15956; c) K. Reichenbächer, H. I. Süss, J. Hulliger, Chem. Soc. Rev. 2005, 34, 22-30.

[8] a) A. W. Markwell-Heys, M. L. Schneider, J. M. L. Madridejos, G. F. Metha, W. M. Bloch, Chem. Commun. 2021, DOI 10.1039/D0CC08076D; b) R. A. S. Vasdev, J. A. Findlay, D. R. Turner, J. D. Crowley, Chem. Asian J. 2021, 16, 39-43; c) L. S. Lisboa, J. A. Findlay, L. J. Wright, C. G. Hartinger, J. D. Crowley, Angew. Chem. Int. Ed. 2020, 59, 11101-11107; d) M. L. Schneider, O. M. Linder-Patton, W. M. Bloch, Chem. Commun. 2020, 56, 12969-12972; e) D. Preston, A. R. Inglis, J. D. Crowley, P. E. Kruger, Chem. Asian J. 2019, 14, 3404-3408; f) S. Klotzbach, F. Beuerle, Angew. Chem. Int. Ed. 2015, 54, 10356-10360; g) A. Dhara, F. Beuerle, Chem. Eur. J. 2015, 21, 17391-17396; h) Kołodziejski, A. R. Stefankiewicz, J.-M. Lehn, Chem. Sci. 2019, 10,1836-1843; for a review see: i) F. Beuerle, B. Gole, Angew. Chem. Int. Ed. 2018, 57, 4850-4878.

[9] a) T. Tozawa, J. T. A. Jones, S. I. Swamy, S. Jiang, D. J. Adams, S. Shakespeare, R. Clowes, D. Bradshaw, T. Hasell, S. Y. Chong, C. Tang, S. Thompson, J. Parker, A. Trewin, J. Bacsa, A. M. Z. Slawin, A. Steiner, A. I. Cooper, Nat. Mater. 2009, 8, 973-978; b) V. Abet, F. T. Szczypiński, M. A. Little, V. Santolini, C. D. Jones, R. Evans, C. Wilson, X. Wu, M. F. Thorne, M. J. Bennison, P. Cui, A. I. Cooper, K. E. Jelfs, A. G. Slater, Angew. Chem. Int. Ed. 2020, 59, 16755-16763; c) M. Liu, L. Zhang, M. A. Little, V. Kapil, M. Ceriotti, S. Yang, L. Ding, D. L. Holden, R. Balderas-Xicohténcatl, D. He, R. Clowes, S. Y. Chong, G. Schütz, L. Chen, M. Hirscher, A. I. Cooper, Science 2019, 366, 613-620; d) R. L. Greenaway, V. Santolini, M. J. Bennison, B. M. Alston, C. J. Pugh, M. A. Little, M. Miklitz, E. G. B. Eden-Rump, R. Clowes, A. Shakil, H. J. Cuthbertson, H. Armstrong, M. E. Briggs, K. E. Jelfs, A. I. Cooper, Nat. Commun. 2018, 9, 2849; e) S. Jiang, Y. Du, M. Marcello, E. W. Corcoran Jr, D. C. Calabro, S. Y. Chong, L. Chen, R. Clowes, T. Hasell, A. I. Cooper, Angew. Chem. Int. Ed. 2018, 57, 11228-11232; f) M. J. Bojdys, M. E. Briggs, J. T. A. Jones, D. J. Adams, S. Y. Chong, M. Schmidtmann, A. I. Cooper, J. Am. Chem. Soc. 2011, 133, 16566-16571.

[10] a) J. C. Lauer, W.-S. Zhang, F. Rominger, R. R. Schröder, M. Mastalerz, Chem. Eur. J. 2018, 24, 1816-1820; b) S. M. Elbert, N. I. Regenauer, D. Schindler, W. S. Zhang, F. Rominger, R. R. Schröder, M. Mastalerz, Chem. Eur. J. 2018, 24, 11438-11443; c) D. Beaudoin, F. Rominger, M. Mastalerz, Angew. Chem. Int. Ed. 2017, 56, 1244-1248; d) M. W. Schneider, I. M. Oppel, A. Griffin, M. Mastalerz, Angew. Chem. Int. Ed. 2013, 52, 3611-3615; e) M. W. Schneider, I. M. Oppel, M. Mastalerz, Chem. Eur. J. 2012, 18, 4156-4160; for reviews about the topic see also: f) M. Mastalerz, Acc. Chem. Res. 2018, 51, 2411-2422; g) M. Mastalerz, Angew. Chem. Int. Ed. 2010, 49, 5042-5053.

[11] T. Jiao, L. Chen, D. Yang, X. Li, G. Wu, P. Zeng, A. Zhou, Q. Yin, Y. Pan, B. Wu, X. Hong, X. Kong, V. M. Lynch, J. L. Sessler, H. Li, Angew. Chem. Int. Ed. 2017, 56, 14545-14550.

[12] a) Q. Liao, C. Ke, X. Huang, G. Zhang, Q. Zhang, Z. Zhang, Y. Zhang, Y. Liu, F. Ning, K. Xi, J. Mat. Chem. A, 2019, 7, 18959-18970; b) B. M. Schmidt, A. K. Meyer, D. Lentz, CrystEngComm. 2017, 19, 1328-1333.

[13] T. Kunde, E. Nieland, H. V. Schröder, C. A. Schalley, B. M. Schmidt, Chem. Commun. 2020, 56, 4761-4764.

[14] S. Jiang, J. T. A. Jones, T. Hasell, C. E. Blythe, D. J. Adams, A. Trewin, A. I. Cooper, Nat. Commun. 2011, 2, 207. 
[15] A. Simonov, A. L. Goodwin, Nat. Rev. Chem. 2020, 4, 657-673.

[16] T. H. Schick, F. Rominger, M. Mastalerz, J. Org. Chem. 2020, 85, 13757-13771. 